\title{
CONCEPT OF ELECTRIC PROPULSION REALIZATION FOR HIGH POWER SPACE TUG
}

\author{
L. E. Zakharenkov, A. V. Semenkin, and A. E. Solodukhin \\ SSC Keldysh Research Centre \\ 8 Onezhskaya Str., Moscow 125438, Russia
}

\begin{abstract}
Popular at the beginning of the Space Age, ambitious projects aimed at Moon, Mars, and other space objects exploration, have returned with new technology and design level. High power space tug with electric propulsion system (EPS) is mainly considered as a transport vehicle for such missions. Modern high power space tugs projects as well as their spacecraft (SC) power and propulsion systems are reviewed in the paper. The main technologies and design solutions needed for high-power EPS realization are considered.
\end{abstract}

\section{INTRODUCTION}

At present, there is a growing interest in radically new space transport vehicle development. High power space tug with EPS is mainly considered as a transport vehicle for implementation of ambitious deep space missions as well as for nearEarth application.

Due to high specific impulse values, electric propulsion application for SC stationkeeping, SC orbit insertion, interplanetary and deep space missions, etc. provides significant fuel saving in comparison with conventional chemical propulsion. So, number of SC with EPS is constantly increasing.

Electric propulsion as a space technology was born in 1960s. During past decades, EPS technology was rapidly progressing. New kinds of electric thrusters appeared and a lot of flight and laboratory EPS models were developed, manufactured, and tested.

Laboratory models of different types of high-power thrusters were intensively researched in 1960s-1970s for providing near-Earth and interplanetary perspective missions $[1,2]$ but they did not find practical application and remained at laboratory level of development. Lack of onboard power needed for electric propulsion supplying was the main reason.

In the last decade of the XX century (1990-2000), main activity was focused on commercial and science electric propulsion application with single thruster 
of kilowatt power level and available onboard power level up to 10-kilowatt level [3,4]. Modern commercial SC onboard power level is about $20 \mathrm{~kW}$ [5] and single thruster power is up to $5 \mathrm{~kW}$. Spacecraft onboard available power level and power of flight electric propulsion are kept constantly increasing. Moreover, 260-kilowatt SC power level is reachable now, it has been demonstrated at the International Space Station (ISS) [4]. Thus, taking into account demonstrated onboard power level and renewal of high power thruster development activity [6-14], there is a good background of the high-power space tugs development.

\section{PROJECTS AND MISSIONS}

There are a number of modern projects aimed at solar $[4,15]$ or nuclear $[16-18]$ electric propulsion tugs development. The power level of considered tugs lies in the range from hundreds of kilowatts up to tens of megawatts.

Collaborative group of Russian enterprises, headed by the Russian Federal Space Agency (Roscosmos) and the State Atomic Energy Corporation "Rosatom," is currently working on an innovative project to create a transport power module (TPM) based on megawatt-class nuclear power propulsion system (NPPS) $[18,19]$.

National Aeronautics and Space Administration (NASA, USA) also shows interest in high-power space tug development. NASA's initial plans provide for stepwise SC onboard power growth $(30 \mathrm{~kW}-90 \mathrm{~kW}-250 \mathrm{~kW})$ up to multimegawatt level in 2026 [20]. One can suppose that space agencies of other countries have such plans or may even have current activities too.

Such projects implementation will allow providing new challenging nearEarth and deep space missions which are hard to realize in other way.

These missions are given below [21]:

- heavy payload transfer to geostationary orbit;

- removal of out-of-operation satellites and space debris from near-Earth orbits;

- Earth protection from asteroid and cometary hazard;

- Moon exploration program;

- Mars manned mission;

- deep space missions; etc.

Projects mentioned therein differ by missions and technical parameters but their analysis allows one to identify common features; general tendencies in a space tug development and technical problem have to be studied and resolved. 


\subsection{Prometheus Project}

The Prometheus Project was an element of the NASA Prometheus Nuclear Systems and Technology Theme. The Project was to develop a Deep Space Vehicle (DSV) for outer solar system robotic exploration missions that would combine a safe, reliable, Space Nuclear Reactor with electric propulsion [16]. The nuclear reactor, the power conversion system (PCS), and the propulsion system were referred to as a nuclear electric propulsion (NEP) system.

Main NEP technologies are:

- primary power source - Nuclear Reactor with Radiation Shield;

- PCS based on gas-turbine Brayton cycle; and

- electric propulsion system based on Ion Thrusters (ITs) and Hall Effect Thrusters (HETs).

The Reactor Module, at the forward end of the DSV (Fig. 1), comprises a high-temperature gas-cooled reactor directly coupled with redundant Brayton turboalternators for power conversion, producing about $200 \mathrm{~kW}$ of electrical power. Aft of the reactor is the Radiation Shield Segment, which provides a conical shadow of reactor radiation attenuation to the remainder of the DSV. Control and monitoring for the reactor is provided by the Reactor Instrumentation and

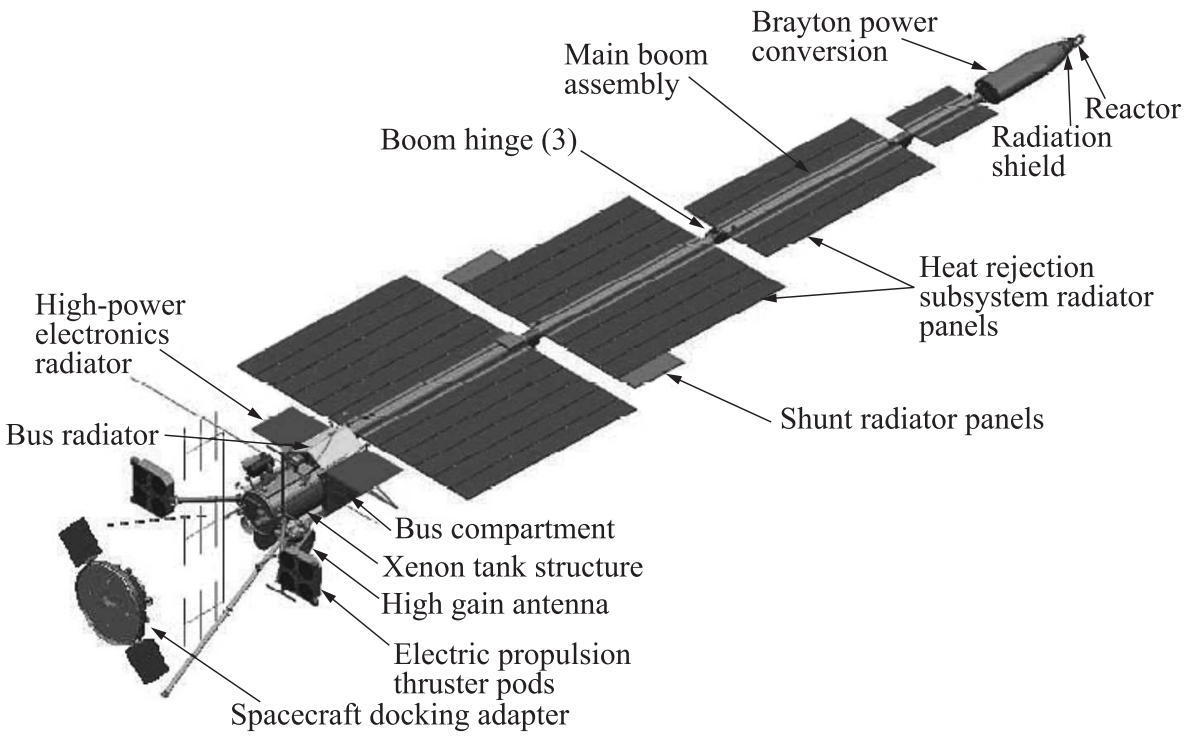

Figure 1 Prometheus project DSV 
Control Segment, with elements located both in the vicinity of the reactor and in the protected areas of the SC bus.

Main propulsion is provided by Ion and Hall thrusters mounted on two deployable thruster pods, making up the Electric Propulsion Segment of the SC Module. An SC docking adapter (Docking Segment) is also included in the SC Module to support early on-orbit operations and docking with the interplanetary transfer stages. The docking adapter provides power, communications, and attitude control functions for the DSV in the postlaunch phases through deployment and commissioning.

The EPS includes ITs and HETs mounted on two pods. Each pod contains four ITs, three large HETs for thrust augmentation, and six small HETs for attitude control. The power and Xenon fuel feeds are controlled internally in the EPS by eight IT Power Processing Units (PPUs) and Xenon Feed Controls (XFCs), respectively, six large HET PPUs and XFCs, and six small HET PPUs and XFCs. Attitude Articulation and Control System (AACS) will control the electric propulsion valve drive electronics.

Unfortunately, the Prometheus Project was directed to not proceed into the next phase [16]. NASA reevaluated its priorities in light of available funding. The Agency nuclear initiatives were postponed to a large extent, and work within the nuclear systems program was reprioritized. Nuclear electric propulsion was given the third priority behind nuclear surface power and nuclear thermal propulsion.

\subsection{High Power Solar Electric Propulsion Freighter}

The use of Solar Electric Propulsion (SEP) can provide significant benefits for the human exploration of near-Earth asteroids. These benefits include substantial cost savings - represented by a significant reduction in the mass required to be lifted to low Earth orbit — and increased mission flexibility [4,22]. The key technology required for the SEP vehicle is the development of an autonomously deployable solar array with approximately $800 \mathrm{~m}^{2}$ of solar cells. For such large high-power solar arrays, mass reducing is provided by operating the array at high voltage. A peak-power voltage of $300 \mathrm{~V}$ was assumed in the vehicle mass estimates. High-power HETs, with an input power of approximately $40 \mathrm{~kW}$, that provide a specific impulse of 2,000 $\mathrm{s}$ and can process over 5,000 kg of Xenon are also required. Direct-drive systems, in which the HETs are operated directly from a high-voltage solar array, are projected to provide significant mass savings, substantially simplify the thermal control subsystem, and facilitate the development of the direct-drive PPU (DDU). Conceptual design of a 300-kilowatt SEP tug is given in Fig. 2.

Solar electric propulsion design power level is a little bit higher than the ISS one $(268 \mathrm{~kW})$. At the same time, SEP solar array design efficiency $(33 \%)$ significantly exceeds the ISS one (11\%) [20] and it will provide considerable reduction 


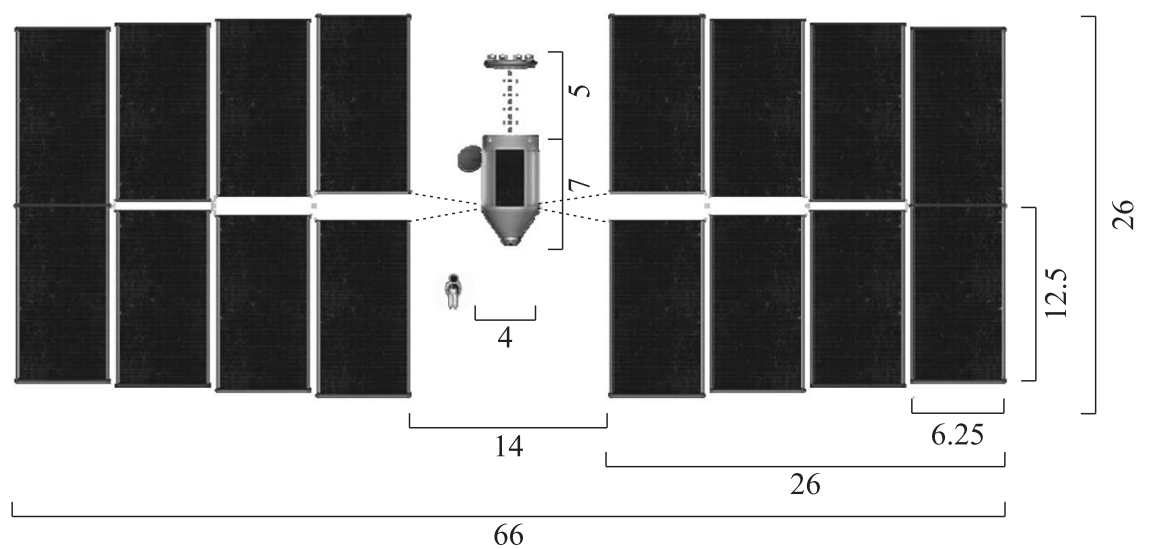

Figure 2 Three-hundred-kilowatt SEP tug. Dimensions are in meters

of solar array overall dimensions and mass. Solar electric propulsion subsystem consists of eight Hall thrusters in which seven are operated simultaneously with a PPU (or DDU) input power of $43 \mathrm{~kW}$ each. Seven Hall thrusters are assumed to be capable of processing the $37,000 \mathrm{~kg}$ of Xenon.

The development of a PPU with the characteristics required for the 300kilowatt SEP Freighter - 43-kilowatt input power; 250- to 350-volt input voltage; 95 percent efficiency; and a mass of $\sim 80 \mathrm{~kg}$ - will certainly be challenging. A high-voltage solar array, with a nominal peak-power output voltage of around $300 \mathrm{~V}$, provides a substantial mass reduction for the SEP vehicle relative to a 100-volt array. A high-power Hall thruster operating at a specific impulse of around 2,000 s requires an anode voltage of around $300 \mathrm{~V}$; therefore, it is natural to utilize direct-drive approach in which the Hall thrusters are operated directly from the high-voltage solar array with a minimum of power processing electronics in between.

The SEP main technologies are:

- primary power source - 33-percent-efficient solar cells array;

- EPS based on HETs; and

- possibility of using DDU instead of conventional PPU.

The main SEP characteristics are:

- 300-kilowatt power solar array;

- single thruster power $\sim 43 \mathrm{~kW}$;

- specific impulse $\sim 2,000 \mathrm{~s}$;

- deployable solar array with approximately $800 \mathrm{~m}^{2}$ of solar cells; and

- storage system with 40,000 kg of Xenon. 


\subsection{Mars-2033 Project}

The Mars-2033 NASA project architecture includes a cargo transfer vehicle (CTV) with NEP system providing $5 \mathrm{MW}$ of electrical power and a crewed Mars transfer vehicle (MTV) with NEP system with two reactors providing a total of 10-megawatt electrical power [23]. Both vehicles use a low-thrust, high-efficiency (5000-second specific impulse) magnetoplasmadynamic (MPD) system to conduct a spiral-out of the Earth gravity well, a low-thrust heliocentric trajectory, and a spiral-in at Mars with arrival in 2033.

The MTV uses two reactors, each providing $5 \mathrm{MWe}$, and a total of four Brayton power conversion units. There are two thruster arms with four $2.5 \mathrm{MWe}$ MPD thrusters (two operational, two spare) on each arm. Each thruster arm has a radiator to reject heat from the PPUs. The total planform area of the PPU radiators is $136.7 \mathrm{~m}^{2}\left(273.4 \mathrm{~m}^{2}\right.$ effective radiating area). Six liquid-hydrogen $\left(\mathrm{LH}_{2}\right)$ tanks that are $7.6 \mathrm{~m}$ in diameter and $19 \mathrm{~m}$ long occupy the middle truss section of the vehicle. The main radiator is comprised of two sections of doublesided flat panels attached to the center truss structure on either side of the propellant tanks due to center-of-gravity requirements. The total planform area of the main radiator is $2722 \mathrm{~m}^{2}$ (5444 $\mathrm{m}^{2}$ effective radiating area). The MTV is $182 \mathrm{~m}$ long and must be assembled in orbit. The configuration of the MTV is shown in Fig. 3.

The EPS of CTV and MTV are based on MPD thrusters with hydrogen as a propellant. The MPD thruster operates at 2.5 MWe at a constant $I_{\mathrm{sp}}$ of $5,000 \mathrm{~s}$ with a thruster lifetime of $7,500 \mathrm{~h}$.

The MTV uses four operating thrusters for a total power level of $10 \mathrm{MWe}$ and has 4 nonoperating spares for redundancy. Likewise, the CTV uses two operating thrusters at a total power level of $5 \mathrm{MWe}$ and has two nonoperating spares for redundancy.

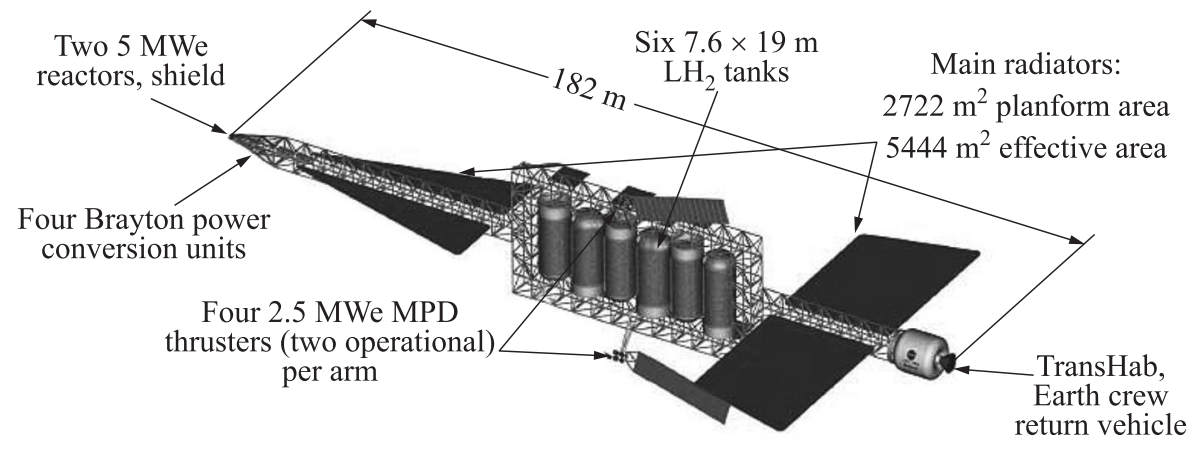

Figure 3 Mars transfer vehicle 
The MTV and CTV main technologies are:

- one or two nuclear reactors;

- four closed gas-turbine Brayton-cycle units;

- panel radiators; and

- MPD thrusters using hydrogen as a propellant.

\subsection{Transport Power Module Project}

An innovative project to create a TPM based on a megawatt-class NPPS is currently being carried out within the framework of cooperation among a group of Russian enterprises headed by the Russian Federal Space Agency (Roscosmos) and the State Atomic Energy Corporation "Rosatom" [16,18]. The main phases of the project are:

2010 - beginning of the Project activity;

2012 - TPM and NPPS draft design development; and

2013-2018 ground testing and TPM flight test preparation.

Main components of NPPS are (Fig. 4):

- gas-cooled fast reactor with nuclear and radiation safety systems as a thermal power source;

- PCS based on gas-turbine Brayton cycle;

- EPS based on ITs with Xenon as a propellant;

- cooler-radiator (droplet or panel type); and

- power management and distribution system (PMAD).

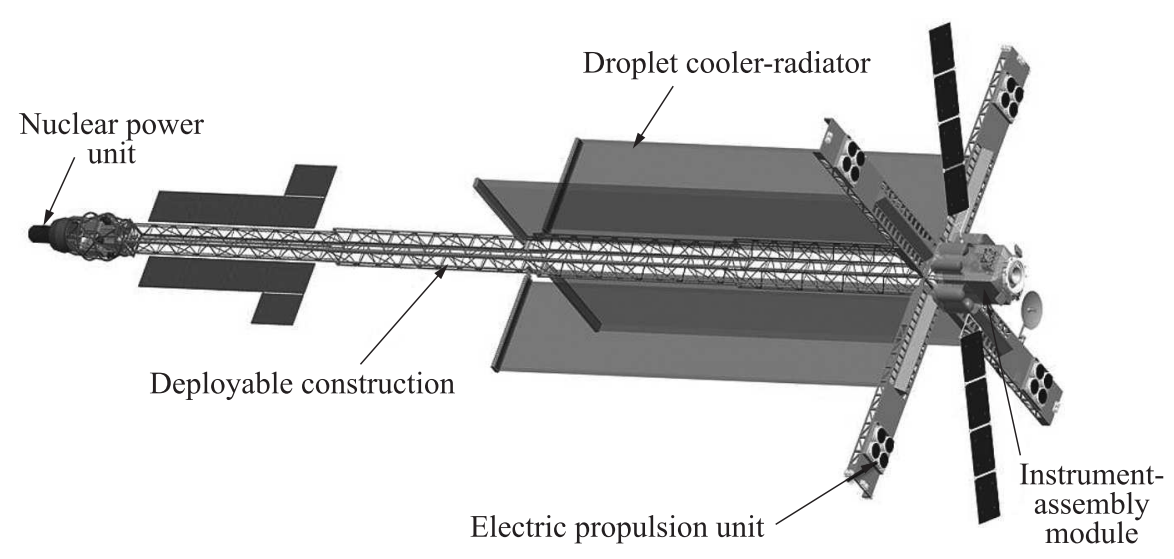

Figure 4 Transport power module based on a megawatt-class NPPS 
The TPM main characteristics are:

- one nuclear reactor of 3.5-megawatt thermal power level;

- four closed gas-turbine Brayton-cycle units for thermal power conversion and generation of 1 MWe;

- PMAD: managing available onboard power $\sim 1$ MWe;

- primary electric propulsion: high-power ITs of total power $\sim 1$ MWe with $I_{\mathrm{sp}} \sim 7000 \mathrm{~s} ;$ and

- electric propulsion for TPM attitude control: ITs with $I_{\mathrm{sp}} \sim 7000 \mathrm{~s}$.

\section{APPROACH AND ISSUES OF ELECTRIC PROPULSION SYSTEM REALIZATION FOR HIGH-POWER SPACE TUG}

Mentioned above space tugs are intended for distinct missions. So, they have power propulsion systems (PPS) based on different power source types and electric propulsion types (Table 1).

Power propulsion system consists of four main components:

(1) Power source;

(2) PCS;

(3) PMAD; and

(4) EPS.

Power source and conversion types selection issues were particularly considered in the previously mentioned projects and, as it was shown, there are some specific features of their combined operation as well as features of interaction with main electric load - EPS [24]. These features should be taken into account while developing PPS operation algorithm. However, EPS and PMAD integration and interference features have not yet been investigated in detail; so, in this paper, some EPS and PMAD design aspects that should be taken into consideration are presented.

In spite of significant distinctions of abovementioned projects, there is a set of common technical solutions related to EPS and PMAD design:

- EPS is based on combining several simultaneously operating thrusters into one assembly referred to as "cluster" [11];

- all considered types of electric propulsion thrusters (IT, HET, and MPD) have cathodes - sources of electrons. These cathodes provide thruster operation and have important function - to neutralize ion fluxes generated by thrusters; 
Table 1 Characteristics of the considered high-power tugs

\begin{tabular}{|c|c|c|c|c|c|}
\hline \multirow{2}{*}{$\begin{array}{c}\text { Project } \\
\text { or tug } \\
\text { name }\end{array}$} & \multirow{2}{*}{$\begin{array}{l}\text { Mission } \\
\text { objective }\end{array}$} & \multicolumn{2}{|c|}{ PPS technologies } & \multirow{2}{*}{$\begin{array}{c}\text { Electric } \\
\text { power, } \\
\mathrm{kW}\end{array}$} & \multirow{2}{*}{$\begin{array}{l}\text { Specific } \\
\text { mass, } \\
\mathrm{kg} / \mathrm{kW}\end{array}$} \\
\hline & & $\begin{array}{c}\text { Power source and } \\
\text { conversion types }\end{array}$ & $\begin{array}{c}\text { Electric } \\
\text { propulsion type }\end{array}$ & & \\
\hline Prometheus & $\begin{array}{l}\text { Jupiter } \\
\text { Icy Moons } \\
\text { Orbiter }\end{array}$ & $\begin{array}{l}\text { Nuclear reactor } \\
\text { with closed } \\
\text { gas-turbine } \\
\text { Brayton cycle }\end{array}$ & $\begin{array}{l}\text { ITs and HETs } \\
\text { using Xenon as } \\
\text { a propellant }\end{array}$ & 200 & $\sim 80$ \\
\hline $\begin{array}{l}\text { SEP } \\
\text { freighter }\end{array}$ & $\begin{array}{l}\text { Near-Earth } \\
\text { missions }\end{array}$ & Solar cell array & $\begin{array}{l}\text { HETs using Xenon } \\
\text { as a propellant }\end{array}$ & 300 & $\sim 36-40^{*}$ \\
\hline TPM & $\begin{array}{l}\text { Near-Earth } \\
\text { and deep } \\
\text { space } \\
\text { missions } \\
\end{array}$ & $\begin{array}{l}\text { Nuclear reactor } \\
\text { with closed } \\
\text { gas-turbine } \\
\text { Brayton cycle }\end{array}$ & $\begin{array}{l}\text { ITs using Xenon } \\
\text { as a propellant }\end{array}$ & 1,000 & $\sim 20$ \\
\hline $\begin{array}{l}\text { MTV } \\
(\mathrm{CTV})\end{array}$ & $\begin{array}{l}\text { Mars } \\
\text { exploration }\end{array}$ & $\begin{array}{l}\text { Nuclear reactor } \\
\text { with closed } \\
\text { gas-turbine } \\
\text { Brayton cycle }\end{array}$ & $\begin{array}{l}\text { MPD thrusters } \\
\text { using hydrogen as } \\
\text { a propellant }\end{array}$ & $\begin{array}{l}10,000 \\
(5,000)\end{array}$ & $\sim 20$ \\
\hline
\end{tabular}

* Lesser value corresponds to DDU option.

- application of so-called "direct drive" concept is proposed. It provides significant cables and transforming electronics mass savings, since the discharge nominal voltage needed for electric propulsion thrusters is supplied directly and there is no need of any intermediate transformation; and

- number of simultaneously operating thrusters can vary in accordance with space tug operation algorithm.

Electric propulsion and power management and distribution systems can have different architecture options that should be considered while analyzing their integration issues. These architecture options and issues are given below.

\subsection{High-Power Electric Propulsion and Power Management and Distribution Systems Architecture}

Electric propulsion system includes thruster, PPU and propellant feed system (PFS). The architecture of typical flight qualified EPS which are under utilization is the following: each thruster has its own PPU and PFS elements.

Multithruster EPS can be designed with the help of two distinct approaches:

(1) integration of several independent EPS; and

(2) creation of cluster assembly with several simultaneously operating thrusters, common PPU, and PFS.

In the second case, it can be considered as a single multichannel thruster. 


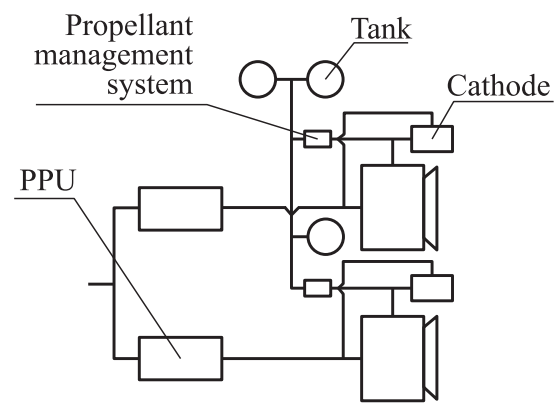

(a)

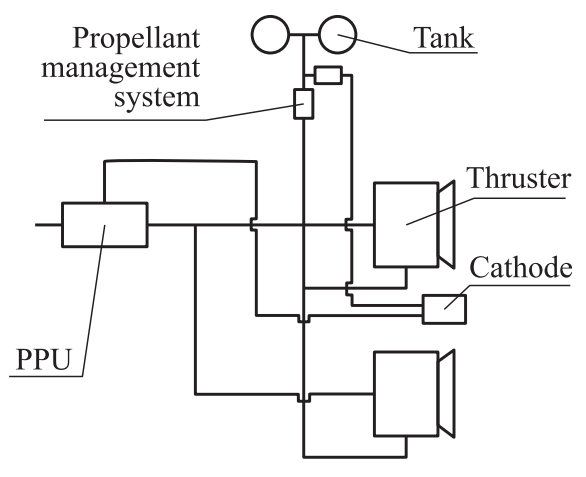

(b)

Figure 5 Independent $(a)$ and common (b) EPS architectures

Two ultimate cases of EPS architecture are given in Fig. 5.

(1) independent EPS architecture (see Fig. 5a) includes a set of independent thruster modules. Each module consists of single thruster, cathode unit, PPU, and PFS. Propellant storage tanks and onboard power system could be common; and

(2) common EPS architecture (see Fig. $5 b$ ) is divided into functionally independent subsystems. A subsystem includes several thrusters, cathode unit, PPU, and PFS. Thus, single PPU, single PFS, and single cathode unit could provide operation of a number of thrusters.

Common EPS architecture allows getting significant EPS mass profit, it also provides the reduction of EPS parts nomenclature and total cost. In addition, the cluster can be optimized for providing required reliability and lifetime using minimal number of thrusters. So, cluster is a quite universal technology and it can be used for the majority of electric propulsion thruster's types.

However, there are some issues that should be taken into account while developing the cluster design. As it was shown before [25-29], several thrusters can operate with common cathode. From the physical point of view, there are no factors limiting the number of thrusters operating with one common cathode. However, when considering EPS transient modes and operation algorithm, such factors come into play.

As it was mentioned above, EPS should provide the possibility of operation of any intermediate number of thrusters from 1 to $N$, where $N$ is the maximal number of simultaneously operating EPS thrusters. The existing flight cathode design allows the emission current to be regulated within a factor of 5 to 10 (see, for example, [30]) without significant reduction of cathode efficiency and lifetime. The value of cathode emission current should be equal to the value of thruster discharge current or to the value of summary discharge currents of 
several operating thrusters. Hence, it appears that the number of thrusters operating with common cathode is limited and determined by the regulation range of cathode emission current. So, for cathode technology, the state-of-theart number of operating thrusters will be 5 to 10 , it will provide the possibility to switch on any number of thrusters from 1 to $N$.

Another EPS cluster architecture feature relates to the possibility of negative interference of thrusters. Electric propulsion thrusters use electric and magnet fields; while operating, they generate high power electromagnetic and thermal radiation. Therefore, there is a danger of negative thrusters interference though Hall- and ion-based clusters tests have shown [28,31-33] that negative interference can be successfully minimized or even entirely eliminated.

Thrusters interference minimization approach consists in optimization of distance between thrusters and in selecting the optimal thrusters assembly configuration. On the one hand, thrusters can be situated at the far distance from each other, but it leads to increasing cluster overall dimensions. On the other hand, in case of thrusters compact arrangement (for example, cluster based on BUSEK BHT-600 Hall thrusters, see [33]), single thruster magnet system switching off could lead to negative effects on magnet systems and operating modes of other thrusters.

As for PMAD, there are the following architecture options: centralized, channelized, or hybrid [34]. Centralized architecture is characterized by the presence of one (central) distribution node. Advantages of the centralized architecture are high efficiency and low mass of the PMAD components. There are several independent nodes in channelized architecture. Advantages of channelized architecture are good fault tolerance and reliability as well as low cabling mass. The most attractive architecture is the hybrid one, since it combines the advantages of the others: modularity; reconfiguration possibility — replacement of any thrusters cluster from any PMAD module (cross ties); highest fault tolerance and reliability as well as good cabling mass and efficiency.

\subsection{Issues of Direct-Drive Concept Realization}

Even without the additional challenges of developing and qualifying new parts, PPUs are expensive and time-consuming to develop. There is the possibility to simplify PPU design and to reduce its mass significantly. At the direct-drive concept realization, the operating voltage of the thrusters is matched to the turbo-alternators or solar array output voltage, eliminating the need for high power direct current (DC) to DC discharge converters.

Electric propulsion thrusters, however, are subject to large-amplitude discharge current oscillations; so, a direct drive system would consist primarily of filtering, switches to isolate thrusters, and low-power auxiliary supplies for cathodes and magnets. If direct drive can be successfully developed, it would result in a significantly higher-efficiency system and significantly less waste heat. It 
could significantly reduce PPU mass with additional savings in structural and thermal management, and array mass. Direct drive systems are potentially much easier to develop than the conventional PPUs, reducing development cost, time, and risk. Direct drive has been studied at power levels up to $1 \mathrm{~kW}$ but successful startup and stable operation at high power with multiple thrusters have been demonstrated [22]. Issues of DDU realization are also discussed in [35,36]. Advantages (without color) and drawbacks (grey color) of DDU-based SEP in comparison with conventional PPU-based are given in Table 2 [34].

Table 2 Solar electric propulsion: conventional PPU-based vs. DDU-based (advantages and drawbacks)

\begin{tabular}{|c|c|}
\hline $\begin{array}{l}\text { Conventional PPU-based } \\
\text { (voltage level 100-160 V) }\end{array}$ & $\begin{array}{c}\text { DDU-based } \\
\text { (voltage level } 300 \mathrm{~V} \text { and higher) }\end{array}$ \\
\hline 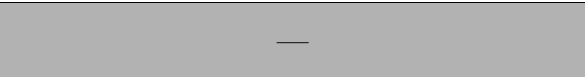 & $\begin{array}{l}\text { Significant EPS mass savings } \\
\text { PMAD mass saving }\end{array}$ \\
\hline $\begin{array}{l}\text { Electronic parts for PPU and PMAD are } \\
\text { commercially available }\end{array}$ & $\begin{array}{l}\text { Electronic parts for DDU and PMAD } \\
\text { mostly are not available } \\
300 \text {-volt solar array technical challenges } \\
\text { include higher electron collection current } \\
300 \text {-volt class solar array designs con- } \\
\text { sistent with de-rated performance of } \\
\text { service-oriented architecture electronic } \\
\text { parts, insulators, gimbal, etc. }\end{array}$ \\
\hline - & $\begin{array}{l}\text { Higher specific power }(\mathrm{kg} / \mathrm{kW}) \\
\text { Superior power efficiency }\end{array}$ \\
\hline $\begin{array}{l}\text { Multimode is available. Discharge volt- } \\
\text { age and current (mass flow rate) can be } \\
\text { varied and there is a possibility to pro- } \\
\text { vide the modes with different combina- } \\
\text { tion of } I_{\mathrm{sp}} \text { and thrust }\end{array}$ & $\begin{array}{l}\text { Only discharge current (mass flow rate) } \\
\text { can be varied } \\
\text { Mode regulation possibility is limited } \\
I_{\mathrm{sp}} \text { cannot be regulated }\end{array}$ \\
\hline- & Significantly less thermal load \\
\hline $\begin{array}{l}\text { Single thruster operation is isolated from } \\
\text { the EPS } \\
\text { Decoupling, galvanic isolation between } \\
\text { the source (array) and thruster }\end{array}$ & $\begin{array}{l}\text { Single thruster operation is not isolated } \\
\text { from the EPS } \\
\text { Bus voltage control is primarily tied to } \\
\text { electric propulsion thruster }\end{array}$ \\
\hline $\begin{array}{l}\text { Simplification of ground testing of in- } \\
\text { dividual components (solar array, EPS, } \\
\text { electric propulsion subsystem) } \\
\text { Simplification of design of solar array } \\
\text { electrical simulator } \\
\text { Prevention of interactions of multi- } \\
\text { thrusters through the power bus }\end{array}$ & $\begin{array}{l}\text { Additional research needed for thruster } \\
\text { stable operation and electric propulsion } \\
\text { startup/shutdown and transition modes }\end{array}$ \\
\hline- & $\begin{array}{l}\text { Cathode current sharing for multi- } \\
\text { thruster operation } \\
\text { Effective grounding schemes }\end{array}$ \\
\hline
\end{tabular}


One of the issues that needs to be solved for DDU realization is the discharge current distribution between several simultaneously operating and galvanically connected cathodes. Cathodes discharge voltage values cannot be absolutely identical, and even a little difference of voltage values can cause significant emission current value changing. Therefore, in the case of cathodes parallel connection, some cathodes would be overloaded and others, inversely, would be underloaded. Cathodes parallel operation can be provided by special means (see, for example, [25]); however, it will require EPS design complication and additional ground testing.

\subsection{Typical Requirements to High-Power Electric Propulsion System Main Components and Testing Issues}

There are special programs aimed at high-power EPS components development [37] (high-power thrusters with high current cathodes [38], gimbals, PPUs, propellant management systems, storage systems, etc.). The most probable thruster candidates for high-power EPS realization are the same as for abovementioned projects (see section 2): HETs [6,9,13,39-42], ITs [7,8,43], and MPD thrusters $[10,14,44]$. Summarizing reference data mentioned above, typical requirements to EPS components can be obtained:

- 20-50-kilowatt thruster with thrust and specific impulse regulation (multimode thruster). The specific mass of thruster is $1-2 \mathrm{~kg} / \mathrm{kW}$;

- cathodes with discharge currents up to hundreds amperes and with the possibility to regulate current values in a wide range;

- PPU specific mass less than $1.8 \mathrm{~kg} / \mathrm{kW}$ of components, efficiency $>95 \%$ at the maximum flight allowable operation temperature of $60{ }^{\circ} \mathrm{C}$. In case of DDU concept realization, the specific mass will be significantly less and the efficiency will be higher;

- the propellant storage system with a low tankage fraction and reduced propellant residuals;

- the propellant management system with precise control of the propellant flow rate; and

- low-mass thruster gimbal.

While considering high-power EPS realization, one more important issue should be mentioned. There are practical limitations for high-power EPS complete cycle of ground testing [45]. The main technical problem is to simulate the environment in which the EPS would operate in space. The existing facilities allow providing a necessary level of vacuum for only single high-power thruster testing. Modernization of existing facilities or building the new one is very expensive; so, it is proposed to use flight demo missions or to create special space platforms to provide flight testing of newly developed high-power EPS key components. 


\section{CONCLUDING REMARKS}

Actual high-power space tug development projects have been analyzed from the point of view of applied technologies. Perspective design solutions for space tug of EPS realization have been considered. It is shown that high-power EPS design should be determined taking into account the interference between EPS and PMAD.

The EPS cluster architecture with direct-drive joint application is the most perspective design direction. However, to realize these concepts, a detailed research aimed at better understanding of operating thrusters interference as well as thrusters interaction within EPS + PMAD assembly should be carried out. During this investigation, EPS and PMAD architectures should be determined, the issue of discharge current distribution between several simultaneously operating and galvanically connected cathodes should be resolved, and negative thrusters interference should be minimized.

\section{REFERENCES}

1. Grishin, S. D., L. V. Leskov, and N. P. Kozlov. 1975. Electric propulsion. Moscow: Mashinostroenie. $270 \mathrm{p}$.

2. Koroteev, A.S., ed. 2006. Manned mission to Mars. Moscow: Russian Academy of Cosmonautics named after K. E. Tsiolkovsky. 320 p.

3. Bennet, G. L., F. M. Curran, D. C. Byuers, J. R. Brophy, and J. F. Stocky. 1994. Enhancing U.S. Competitiveness: The NASA Electric Propulsion Program. AIAA Paper No. 1994-2735.

4. Brophy, J. R., R. Gershman, N. Strange, D. Landau, R. G. Merrill, and T. Kerslake. 2011. 300-kW solar electric propulsion system configuration for human exploration of near-Earth asteroids. AIAA Paper No. 2011-5514.

5. Kessler, T. 2011. Solar electric propulsion. Evolving capability supporting multiple users and missions. Boeing Advanced Systems.

6. Jacobson, D. T., and R.S. Jankovsky. 1999. Performance evaluation of $50 \mathrm{~kW}$ Hall thruster. AIAA Paper No. 99-0457.

7. Randolph, T. M., and J.E. Polk. 2004. An overview of the nuclear electric xenon ion system (NEXIS) activity. AIAA Paper No. 2004-3450.

8. Elliott, F. W., J.E. Foster, and M. J. Patterson. 2004. An overview of the high power electric propulsion (HiPEP) project. AIAA Paper No. 2004-3453.

9. Zakharenkov, L. E., A. Semenkin, S. Tverdohlebov, A. Sengupta, and C. MarreseReading. 2007. Development and study of the very high specific impulse bismuth TAL. IEPC Paper No. 2007-128.

10. Gorshkov, O.A., V.N. Shutov, K.N. Kozubsky, V.G. Ostrovsky, and V.A. Obukhov. 2007. Development of high power magnetoplasmadynamic thrusters in the USSR. IEPC Paper No. 2007-136.

11. Zakharenkov, L.E., and A. V. Semenkin. 2011. Multi-thruster electric propulsion system architecture and ways of simultaneously operating thrusters interaction. 4th European Conference for Aerospace Sciences (EUCASS). 
12. Semenkin, A. V., L. E. Zakharenkov, and A. E. Solodukhin. 2011. Feasibility of high power multi-mode EPS development based on the thruster with anode layer. IEPC Paper No. 2011-064.

13. Florenz, R., A.D. Gallimore, and P. Y. Peterson. 2011. Developmental status of a 100-kW class laboratory nested channel Hall thruster. IEPC Paper No. 2011-246.

14. Albertoni, R., P. Rossetti, F. Paganucci, M. Andrenucci, M. Zuin, E. Martinez, and R. Cavazzana. 2011. Experimental study of a 100-kW class applied-field MPD thruster. IEPC Paper No. 2011-110.

15. Myers, R., and Ch. Carpenter. 2011. High power solar electric propulsion for human space exploration architectures. IEPC Paper No. 2011-261.

16. National Aeronautics and Space Administration. 2005. Prometheus Project. Pasadena, CA: Jet Propulsion Laboratory. Final Report No. 982-R120461.

17. Koroteev, A. S. 2010. High efficiency space transportation system based on nuclear power and propulsion. FP8 Space Research Hearing. Brussels. Available at: http:/ /ec.europa.eu/enterprise/policies/space/files/research/fp8_space_hearing/prese ntations/gorshkov-oleg_en.pdf (accessed June 1, 2015).

18. Russian Federation. February 6-17, 2012. Implementation of the safety framework for nuclear power source applications in outer space. Modern and Planned Applications and Challenges Workshop, 49th session. Vienna: Scientific and Technical Subcommittee of the United Nations Committee on the Peaceful Uses of Outer Space. 22 p. Available at: http://www.unoosa.org/pdf/pres/stsc2012/2012nps-02E.pdf (accessed June 1, 2015).

19. Koroteev, A.S. 2012. New stage of space energetics evolution. Herald of the Academy of Sciences 82(4):317-322.

20. Patterson, M. 2010. A new space enterprise of exploration. Review. NASA. 21 p. Available at: http://www.nasa.gov/pdf/458818main_FTD_SolarElectricPropulsion Stage.pdf (accessed June 1, 2015).

21. Koroteev, A.S. 2009. Significant objectives of space exploration in the 21st century. 1st Symposium on Space and Global Security of Humanity. Limassol, Cyprus.

22. Polk, J. E., H. Kamhawiy, K. Polzinz, J. Brophy, J. Ziemer, T. D. Smith, and M. LaPointe. 2011. An overview of NASA's electric propulsion programs, 2010-11. IEPC Paper No. 2011-330.

23. McGuire, M. L., M. C. Martini, T. W. Packard, J. E. Weglian, and J. H. Gilland. 2006. Use of high-power Brayton nuclear electric propulsion (NEP) for a 2033 Mars round-trip mission. NASA/TM Paper No. 2006-214106.

24. Karevsky, A. V., and S. A. Popov. 2013. The special features of the combined operation of the energy conversion system and electric propulsions integral with the nuclear power propulsion system. 5th European Conference for Aerospace Sciences (EUCASS).

25. Rusakov, A.V., A. V. Kochergin, A.V. Semenkin, S. O. Tverdokhlebov, and V. I. Garkusha. 1997. Multiple thruster propulsion systems integration study. IEPC Paper No. 97-130.

26. Zakharenkov, L. E., A. V. Semenkin, A. V. Rusakov, N. A. Urchenko, S. O. Tverdokhlebov, V. I. Garkusha, U. V. Lebedev, S. N. Podkolsin, and J. M. Five. 2003. Study of multithruster assembly operation. IEPC Paper No. 2003-0311.

27. Beal, B.E., A. D. Gallimore, and W. A. Hargus. 2005. The effects of cathode configuration on Hall-thruster cluster plume properties. AIAA Paper No. 2005-3678. 
28. Patterson, M. J., J. Foster, H. McEwen, E. Pencil, J. Van Noord, and D. Herman. 2006. NEXT multi-thruster array test - engineering demonstration. AIAA Paper No. 2006-5180.

29. Walker, M. L. R., and A.D. Gallimore. 2007. Hall thruster cluster operation with a shared cathode. J. Propul. Power 23(3):528-536. doi: 10.2514/1.23688.

30. Polk, J.E., D. Brinza, R.Y. Kakuda, J.R. Brophy, I. Katz, J. R. Anderson, V.K. Rawlin, M. J. Patterson, J. Sovey, and J. Hamley. 2001. Demonstration of the NSTAR ion propulsion system on the deep space one mission. IEPC Paper No. 01-075.

31. Beal, B. E. 2004. Clustering of hall effect thrusters for high-power electric propulsion. Ann Arbor, MI: Aerospace Engineering Department, University of Michigan. Ph.D. Diss.

32. Zakharenkov, L.E., A. V. Semenkin, V.I. Garkusha, and Y.V. Lebedev. 2005. Study of the 3-TAL thruster assembly operation. IEPC Paper No. 2005-185.

33. Lobbia, R. B., and A. D. Gallimore. 2007. Performance measurements from a cluster of four Hall thrusters. IEPC Paper No. 2007-177.

34. Kerslake, T. W., K. M. Bury, J. S. Hojnicki, A. M. Sajdak, and R. J. Scheidegger. 2011. Solar electric propulsion (SEP) tug power system considerations. NASA/TM Paper No. 2011-217197.

35. Dankanich, J. 2005. Direct drive for low power Hall thrusters. AIAA Paper No. 2005-4118.

36. Brandhorst, H., S. Best, Julie Rodiek, M. O'Neill, and M. Piszczor, Jr. 2010. Directdrive performance of a T-100 HET powered by a triple junction, high-voltage concentrator PV array. AIAA Paper No. 2010-6620.

37. Randolph, T. M. 2007. Qualification of commercial electric propulsion systems for deep space missions. IEPC Paper No. 2007-271.

38. Goebel, D. M., and E. Chu. 2011. High current lanthanum hexaboride hollow cathodes for high power Hall thrusters. IEPC Paper No. 2011-053.

39. Kim, V., G. Popov, B. Arkhipov, V. Murashko, O. Gorshkov, A. Koroteyev, V. Garkusha, A. Semenkin, and S. Tverdokhlebov. 2001. Electric propulsion activity in Russia. IEPC Paper No. 01-05.

40. Manzella, D. H., R. S. Jankovsky, and R. R. Hofer. 2002. Laboratory model $50 \mathrm{~kW}$ Hall thruster. AIAA Paper No. 2002-3676.

41. Jacobson, D. T., D. H. Manzella, R. R. Hofer, and P. Y. Peterson. 2004. NASA's Hall Thruster Program. AIAA Paper No. 2004-3600.

42. Florenz, R., T. M. Liu, A. D. Gallimore, H. Kamhawi, D. L. Brown, R. R. Hofer, and J. E. Polk. 2012. Electric propulsion of a different class: The challenges of testing for megawatt missions. AIAA Paper No. 2012-3942.

43. Polk, J. E., D. M. Goebel, J. S. Synder, A. C. Schneider, L. K. Johnson, and A. Sengupta. 2005. Performance and wear test results for a $20 \mathrm{~kW}$-class ion engine with carbon-carbon grids. AIAA Paper No. 2005-4393.

44. De Tata, M., R. Albertoni, P. Rossetti, F. Paganucci, M. Andrenucci, M. Cherkasova, V. Obukhov, and V. Riaby. 2011. 100-hr endurance test on a tungsten multi-rod hollow cathode for MPD thrusters. IEPC Paper No. 2011-108.

45. Jankovsky, R., S. Tverdokhlebov, and D. Manzella. 1999. High power Hall thrusters. AIAA Paper No. 99-2949. 